\title{
The Inherited Bone Marrow Failure Syndromes
}

\author{
S. Deborah Chirnomas, MD, MPH [Director, Pediatric Stem Cell Transplant Program \\ Assistant Professor of Pediatrics] and Gary M Kupfer, MD [Chief, Section of Pediatric \\ Hematology Oncology Professor of Pediatrics and Pathology] \\ Yale School of Medicine New Haven, CT
}

\begin{abstract}
In spite of the rarity of inherited bone marrow failure syndromes (IBMFS), they represent diseases for which the molecular pathogenesis may be elucidated. Their study and presentation of the details of their molecular biology and biochemistry is warranted not only for appropriate diagnosis and management of afflicted patients but also because they lend clues to the normal physiology of the normal hematopoiesis and, in many cases, mechanisms of carcinogenesis. Several themes have emerged within each subsection of IBMFS, including the ribosomopathies that entail both ribosome assembly as well as ribosomal RNA processing. The Fanconi anemia (FA) pathway itself has become interdigitated with the familial breast cancer syndromes. The sections that follow present a more detailed analysis of the diseases that account for the majority of IBMFS diagnoses.
\end{abstract}

\section{Keywords}

ribosomopathies; Fanconi anemia; Diamond Blackfan anemia; dyseratosiscongenita; Shwachman Diamond; Bone marrow failure; DNA repair; Ribosome biogenesis; Cancer susceptibility

In spite of the rarity of inherited bone marrow failure syndromes (IBMFS), careful studies of the molecular pathogenesis of these disorders has led to a deeper understanding of normal and aberrant bone marrow function. Understanding the molecular biology and biochemistry of IBMFS helps in the appropriate diagnosis and management of afflicted patients and also lends clues to the physiology of normal hematopoiesis and, in many cases, elucidates mechanisms of carcinogenesis. Several themes have emerged within each subsection of IBMFS, including the ribosomopathies that include both ribosome assembly as well as ribosomal RNA processing. The Fanconi anemia (FA) pathway itself has become interdigitated with the familial breast cancer syndromes. The sections that follow present a more detailed analysis of the diseases that account for the majority of IBMFS diagnoses.

\section{A. The Ribosomopathies}

In recent years, the subset of patients affected with Diamond_Blackfan anemia (DBA), Shwachman-Diamond-Bodian Syndrome (SDBS), dyskeratosiscongenita (DC), and cartilage hair hypoplasia $(\mathrm{CHH})$ have all been shown to have mutations in ribosomal proteins and in proteins responsible for processing of ribosomal RNA[1]. The reports of

(C) 2013 Elsevier Inc. All rights reserved

Corresponding Author: Gary.Kupfer@yale.edu.

Publisher's Disclaimer: This is a PDF file of an unedited manuscript that has been accepted for publication. As a service to our customers we are providing this early version of the manuscript. The manuscript will undergo copyediting, typesetting, and review of the resulting proof before it is published in its final citable form. Please note that during the production process errors may be discovered which could affect the content, and all legal disclaimers that apply to the journal pertain. 
amelioration of a DBA-like phenotype in the p53 deficient mouse and zebrafish imply that defects in the ribosome assembly pathway and imbalances in protein synthesis lead to cell stress that can activate the p53 pathway and cause subsequent apoptosis, resulting in a depletion of sensitive cell populations such as the hematopoietic stem cell pool[2][3]. Even though the biology of these syndromes does not completely overlap (i.e., DC involves biology directly at the telomere), several investigators have organized these diseases into a linear or cooperative pathway in which ribosomal RNA is assembled in a multistep process. [4]

\section{Diamond-Blackfan Anemia (DBA)}

The most common disease of isolated inherited red cell production failure is DBA, with an incidence is approximately 5-7 cases per million live births in North America. Presentation of the disease can be at any age but the majority of patients are diagnosed in the first year of life with at least $10 \%$ in one series presenting at birth and $25 \%$ within the first month of life. $[5][6][7][8][9]$.

DBA is a genetic disease with evidence of mixed inheritance, although sporadic cases comprise the majority of all cases. A significant portion of inherited cases is autosomal dominant with equal sex frequency. This group of patients appear to have fewer physical anomalies. Another portion of cases is autosomal recessive with disproportionately more males than females, implying an X-linked form of the disease[10][11][12].Approximately $50 \%$ of DBA patients exhibit physical abnormalities, including dysmorphicfacies, short stature, eye, kidney, and hand abnormalities[13][14][15]. Patients first present typically with macrocytic anemia and reticulocytopenia and associated pallor, often in the setting of failure to thrive. In the neonatal period, diagnosis can be uncertain, as the normal newborn proceeds through the physiological nadir of erythropoiesis over the first 4-8 weeks and the normal newborn RBC is macrocytic at birth. Thus, most commonly, patients present between 2 and 4 months of age. The confirming finding is reticulocytopenia and decreased erythroid activity in the bone marrow [16][17].

In addition, significant minorities of patients present with neutropenia, thrombocytosis, or thrombocytopenia, even though DBA is thought of as a pure red cell aplasia[18]. Other nonspecific abnormalities include elevations of fetal hemoglobin, red cell antigen $\mathrm{i}$, iron, folate, and B12[16][17] An elevated erythrocyte adenosine deaminase level has been proposed as a good diagnostic test for DBA with a sensitivity of $84 \%$ and specificity of $95 \%$. However, $16 \%$ of affected people will have a normal erythrocyte adenosine deaminase[19].

The two most common therapeutic options are corticosteroids or transfusion therapy for patients that are symptomatic from their anemia. Corticosteroids may be initiated with anemia that causes cardiovascular and developmental compromise. Prednisone is usually the first line agent at a dose of $2 \mathrm{mg} / \mathrm{kg} / \mathrm{day}$. If the child has a response to steroids, the goal is to reach a hemoglobin of $10 \mathrm{~g} / \mathrm{dl}$ and sustained reticulocytosis after which the steroids can be slowly tapered off. . A bit more than half of DBA patients are steroid responders; within this group, many can be weaned to a very low dose or off prednisone completely[20][15][21]. Corticosteroids may become problematic with chronic use, leading to growth retardation, weight gain, gastritis, and decreased bone mineralization. Interestingly, those who are positive responders display a distinctive gene expression signature that may characterize the underlying difference in response as host related.

For patients who do not respond to steroids or cannot tolerate them, transfusion therapy is an effective option. As is the case with chronic transfusion therapy for any disease, iron overload becomes the chief difficulty, resulting in cardiac, endocrine, and pulmonary disease. Chronic iron chelation using subcutaneous desferoxamine has been poorly tolerated 
and adherence limited. Since 2006, deferasirox, a daily oral chelator, has been available for treatment of iron overload and in more recently, deferiprone, an oral agent given three times a day was FDA approved for use in this setting[22].

Any discussion of transfusion and iron overload must be balanced against the role of bone marrow transplantation (BMT) as a curative modality with its associated side effects. The side effects of BMT include graft versus host disease (GVHD), infections, and chemotherapeutic toxicity involved with conditioning. With matched sibling donors, the risk of GVHD has become markedly lower with long term survival of over $80 \%$. The optimal timing of BMT in DBA is not known. The younger patient is more likely to exhibit less GVHD and better long-term survival but have more late effects, leading some to argue for waiting for additional time to allow for late remissions [23][24].

Growth factors have also been used in DBA. Erythropoietin has been the logical choice without any evidence of efficacy[25]. IL-3 has shown some modest benefit amongst transfusion-dependent patients, along with side effects of deep venous thromboses and constitutional symptoms[26][27]. In recent years additional agents have been shown to be at least anectdotally beneficial, including leucine and metaclopropamide.

Patients with DBA have a reduced life expectancy from causes largely related to treatment side effects and long term risks of malingancy. In addition, hematologic malignancy is a major cause of death asDBA patients have a risk of AML with a lifelong risk of up to 25\%[28]. Anecdotally ALL, Hodgkin's, and MDS have all been reported in DBA[29][30] [31][32]. Reports of osteogenic sarcoma and hepatocellular carcinoma, which are likely associated with concomitant viral hepatitis infection, have also been published [33][34]. An overall risk of 5.4 odds ratio for developing cancer in DBA has been calculated, with predominance in MDS, AML, colon cancer, osteogenic sarcoma, and genital cancer.

Often mentioned in the differential diagnosis of DBA are transient erythrocytopenia of childhood (TEC) and infection with parvovirus. TEC and parvovirus induced aplasia should resolve within a month and both are unusual in the newborn period.

The science of DBA has exploded in the last decade. The first gene identified as mutated in DBA, ribosomal protein RPS19, was cloned positionally by analyzing a patient with DBA who had a translocation interrupting the RPS19 locus. Twenty-five percent of DBA patients have RPS19 mutations in the heterozygous state, which implies that the allele acts in a dominant negative fashion or that a dosage effect exists and that the presence of 2 mutated alleles may be lethal [35][36]. As many as 8 additional mutations in ribosomal genes have been identified, both in the large as well as the small subunit of the ribosome (RPL5, RPL11, RPL15, RPL35, RPS7, RPS10, RPS17, RPS24, RPS26), leaving almost 50\% of DBA cases having no identified mutation[37]. A recent report detailed the first nonribosomal mutation found in a DBA patient, exhibiting a GATA splice site mutation [38].

The cloning of these genes alone does not answer the basic question of why DBA occurs. In general, reduced colony forming activity in DBA patients has been observed, but this has not proven to be a reliable predictor of DBA[39][40][41][42]. Progenitors have been marked by accelerated apoptosis[43]. Defects in the microenvironment of the marrow have also been proposed as contributors to pathogenesis because of inhibition of erythropoiesis by bone fragments from a DBA patient. Other affected functions include growth factors, their receptors, and transciption factors[44].

A mouse with an RPS19 knockout showing the DBA phenotype has been made and is being studied. As noted above, increased understanding of DBA came through amelioration of its phenotype in a p53 knockout background in both the mouse and the zebrafish, leading to a 
lower rate of apoptosis and suggesting that the imbalance of ribosome synthesis and/or inefficiency of protein translation leads to cell stress. In addition, RPS26 has been demonstrated through an RPL11 mediated pathway to stabilize p53 via interaction in an inhibitory fashion with MDM2, which is the E3 ubiquitin ligase for p53, thus leading to the stabilization of p53 [45].

An interesting overlap with adult MDS has been characterized in the identification of the etiology of the 5q- syndrome, which arises as a result of deletion of the RPS14 gene. This acquired defect leads to a lower risk MDS that has been treated with lenalidomide[46][47].

\section{DyskeratosisCongenita}

Dyskeratosiscongenita (DC) is a genetically heterogeneous disorder related to defects in telomere maintenance. The classic X-linked recessive form in particular appears to be associated with the classic DC findings of hyperpigmented reticular lacy pigmented skin, dystrophic nails, and leukoplakia. Up to 90 percent of patients develop bone marrow failure, although the time to recognition of classic findings is quite variable. The inheritance pattern can also be autosomal dominant or autosomal recessive. Two particularly severe variants are Hoyeraal-Hreidarsson $(\mathrm{HH})$, presenting as systemic DC with cerebellar hypoplasia and developmental dysfunction and Revesz syndrome, similar to HH coupled with exudative retinopathy. Reported cases have included probands with intrauterine growth retardation and microcephaly. In addition, these patients have a predisposition to myelodysplasia, myeloid leukemia, and an assortment of solid tumors, including squamous cell cancers of the head, neck, and anogenital region[48][49][20][50]. As in numerous genentic cancer predisposition syndromes, sporadic mutations have been found in DC genes in cancers, suggesting the importance of the telomere broadly in cancer outside of DC.

On a cellular level DC cells are characterized by progressive telomere shortening that accumulates in an age-dependent fashion, thus leading to variability in the phenotype. In fact, the age of presentation has been reported to be as high as 75 years. When a patient with bone marrow failure does present, given the clinical heterogeneity of many of these disorders in question, telomere analysis should be a part of the workup for all bone marrow failure. While some variability exists in telomere length analysis, overall it is a sensitive test for DC, and combination analysis with flow cytometry to measure telomeres in multiple cell subsets can enhance its utility[51].

The first identified gene DKC is X linked (and the most common form of DC), encoding the dyskerin protein that resides in ribonucleoprotein (RNP) complexes at the telomere as well as in ribosomal RNA. This implies a duality in mechanism of the proteins involved in DC. Dyskerin binds to the RNA that serves as the template for the TTAGGG repeats found at telomeres. Other members of the telomerase RNP found to be causative when mutant in DC include NOP10, NHP2, TCAB1, TERC and TERT (telomerase reverse transcriptase), all of which are autosomal recessive inheritance[52][53][51]. Dyskerin also appears to be involved in the pseudouridylation of rRNA, but the specific function in the ribosome of this modification is unclear[54].

The other genes responsible for DC reside in the shelterin complex that protects telomeres from degradation. Shelterin is a 6-member protein complex that includes the DC causative gene TIN2. The function of the shelterin complex is to protect telomeres from exonuclease activity, thus enabling the integrity of telomere length[52].

The classical presentation of DC includes two of the three following findings: dystrophic nails, a reticular lacy rash, leukoplakia. Other features recognized to be part of the DC spectrum include premature graying hair, pulmonary fibrosis, liver disease, leukemia or 
MDS, esophageal stenosis, urethral stenosis, short stature and developmental delay. Recently described is the high prevalence of neuropsychiatric disorders in this population, which has previously been reported as $25 \%$ in children but in a recent small prospective study done by the NCI, the lifetime risk for children with DC was $83 \%$ for disorders including ADHD, PDD, anxiety and mood disorders[55].

The diagnosis of DC can be difficult with still close to $50 \%$ of patients lacking a known mutation in the DC pathway. The measurement of telomere lengths in lymphocyte subsets has become an important element that supports a diagnosis of DC. Patients with DC have very short telomeres well below the normal range in contrast to other IBMFS patients who often have short telomeres compared to the general population but are not significantly shorter than the first percentile. Clinicians must use a combination of physical exam findings, family history, and features of leukemia or bone marrow failure and/or very short telomere lengths. Often, the family history can be particularly useful in anticipating new patients who may have worse disease than their forebears, perhaps because the telomere inheritance gets shorter and shorter with each generation.

Management of DC generally centers around treating the symptoms of marrow failure. Because the treatment options have significant morbidity, a watch and wait approach is often employed. When cytopeniascause symptoms, androgens can be used to good effect despite masculinizing side effects and the need for careful monitoring for liver tumors later in life. The use of growth factors has achieved some temporary improvement in counts and related symptoms, but worry of malignant transformation in the resultant stressed marrow remains a concern[56][57].

If those therapies do not help, BMT can be considered. Unfortunately, outcomes for BMT have been poor based both on patients' sensitivities to conditioning regimens as well as the underlying disease. DC patients are unique in having very late pulmonary and liver complications, likely due to their underlying disease, that may be worsened or accelerated by the transplant process. Recent data from 2013 looking at 34 patients treated from 1981 to 2009 reported a 10 year survival probability of 30\%. Unrelated donors or mismatched related donors and regimen intensity were independent risk factors for early mortality[58] [59][60].

\section{Shwachman-Diamond syndrome}

Shwachman-Diamond syndrome (SDS) is a syndrome of neutropenia, pancreatic exocrine function insufficiency, and metaphysealdysostosis. Anemia and thrombocytopenia can indeed accompany the neutropenia. SDS patients also can have a wide array of physical findings, including short stature, failure to thrive, skin rashes and macules, teeth and palatal defects, and syndactyly[7][61][62]. The putative gene which when mutated leads to SDS is the SBDS gene, encoding a 250 amino acid protein with predicted functions in RNA metabolism. Its widespread expression may be the basis of the multiple organ involvement of SDS [63]. A recent model using induced pluripotent stem cells as a model for SDS manifests exocrine and hematopoietic cell dysfunction that phenocopies SDS[64]. Recent work demonstrates the defective processing of rRNA into ribosome assembly, suggesting that SDS is closely associated with the molecular pathogenesis of DBA [65]. A majority of SDS patients do not display a mutation in the SBDS gene, suggesting additional genes underlying the pathogenesis of SDS. The diagnosis of SDS can be difficult, as many patients do not have an identifiable mutation in SBDS gene. Clues can be found by examining trypsinogen, isoamylase, and obtaining an ultrasound of the pancreas. Family history may provide a clue but is less useful than in DC. 
No definitive therapy exists for SDS neutropenia, except for bone marrow transplantation, while pancreatic insufficiency is managed by administration of exogenous pancreatic enzymes. Supportive care is indicated with transfusions in the $20 \%$ of SDS patients who develop pancytopenia. Some efficacy has been reported with the use of granulocytestimulating growth factors, with 6 out of 7 responding to G-CSF in one series. Like other IBMFS, the diagnosis of SDS confers a $\%$ risk of leukemia, including ALL, CML, and AML, making the use of growth factors a difficult decision for fear of stimulating a clonal expansion, despite minimal data to support this concern [66][67][68].

\section{Cartilage hair hypoplasia}

Cartilage hair hypoplasia $(\mathrm{CHH})$ is a recessive disease with a constellation of skeletal abnormalities consisting of short stature,lordosis, scoliosis, and chest wall deformities. The disorder was first described amongst the Old Order Amish. Sparse, fine hair is the other consistent feature[69][70]. Growth failure occurs prenatally with shortness of limbs or stature noted on fetal ultrasound or perinatally. CHH patients also have increased risk of Hirschsprung's disease[71]. Mutations in the RNA component of RNAse MPR endoribonuclease involved in mitochondrial and nucleolar RNA processing has been reported to be responsible for $\mathrm{CHH}$ [72]. Together with TERT, the telomerase reverse transcriptase, RMRP forms a complex that produces double strand RNA that participates in small interfering RNAs[73]. RMRP works in parallel with Diamond-Blackfan anemia defects, upstream of Shwachman-Diamond, and downstream of dyskeratosiscongenita in the processing of the $80 \mathrm{~S}$ unit of the ribosome[74].

Anemia and macrocytosis occurs in the variable context of pancytopenia[75]. Lymphopenia is reported along with defective cellular immunity[76]. Corticosteroids and transfusion have been used temporarily with some patients outgrowing marrow failure[77]. However, increased malignancy risk was also reported throughout infancy, childhood, and adulthood[69][78]. T cell lymphoproliferative disease has been seen as a consequence of immunodeficiency [79].

\section{B. Fanconi anemia (FA)/BRCA Pathway}

Fanconi anemia (FA) is an autosomal and X-linked recessive disorder characterized by bone marrow failure, acute myelogenous leukemia (AML), solid tumors, and developmental abnormalities. At the molecular level, cells derived from FA patients display hypersensitivity to DNA cross-linking agents, resulting in increased numbers of chromosomal abnormalities including translocations and radial chromosomes. This hypersensitivity has made successful treatment for FA patients a challenge in the past because traditional treatments of symptoms resulted in more harm than good. In recent years, care of the FA patient has improved with modern blood banking, antibiotics, and hematopoietic stem cell transplantation (SCT), which has been used in performed in FA patients for almost 30 years[80].Despite greater survival of children into adulthood as a result of SCT, the specter of the potential for solid tumors, such as squamous cell carcinomas of the head, neck, and genitourinary track, remains a serious problem[81][82].

Even though the classic features of thumb abnormalities and radius absence generally characterize these patients, FA children typically present in the first decade of life upon recognition of aplastic anemia[83][84][85]. Even more interesting is the fact that a sizable subset of FA patients has no discernible abnormalities at all. As a result, the index of suspicion of the clinician must be high to recognize the diagnosis of FA in the differential diagnosis of aplastic anemia. 
The gold standard tests for FA quantify chromosomal breakage in cells exposed to crosslinking agents to which FA cells are hypersensitive, typically diepoxybutane[80,85].On occasion, despite the strong suspicion of FA being present in a patient, the chromosome fragility test can be negative due to somatic reversion[86][87]. In the face of this possibility, if a negative diepoxybutane or mitomycin $\mathrm{C}$ result has been obtained in the setting of strong suspicion of an FA diagnosis, then a skin biopsy should be obtained for culture and subsequent diepoxybutane testing.

Ninety percent of FA patients first present with bone marrow failure, but a percentage present nonetheless first display AML. These cases of AML are typically M1-M4 FAB subtype and display no characteristic cytogenetic or molecular abnormality, although numerous translocations, deletions, and other aneuploidogenic changes can be found[88].Some report distinctly different clones in FA-associated AML versus sporadic AML [89]. Patients treated in a fashion similar to other AML patients experience intolerance to standard doses of alkylating agents. Thus, morbidity precludes an aggressive approach. In addition, analysis of cells derived from these AML cases suggests that some are paradoxically resistant, perhaps a result of the underlying genomic instability of FA cells that could allow acquisition of resistance[90].

FA patients are at markedly increased risk of squamous cell carcinomas (SCC) of the head and neck and genitourinary tract. These tumors have been only sporadically positive for human papilloma virus, although vaccination for HPV is strongly encouraged in the FA population. In addition, routine laryngoscopy and ENT follow up is considered standard of care for FA patients[81][82][91]. Breast cancer is also typical of adult FA patients, which is in line with the fact that 5 FA genes are actual familial breast cancer genes: BRCA2, PALB2, RAD51C, SLX4, and BACH1[92,93][94][95][96].

FA genes have also been implicated in sporadic cancers by virtue of detection of non germline mutations in tumors such as lung, pancreatic, ovarian, and breast. It has been proposed that such tumors can be targeted by using agents specifically inducing hypersensitivity in FA mutant cells[97].

Because the FA patient is at increased risk of toxicity from SCT regimens, clinicians must time the procedure before the onset of leukemia, avoiding the long-term effects of blood product provisionorunaffected by serious infectionsfrom invasive organisms like Aspergillus. The complementation group and gene mutation should be identified in order to assess the suitability of a family member stem cell donor, averting the possibility that a matched donor has a subclinical case of FA. It has become clear from the experience of FA clinicians that FA-D1 and those with the Ashkenazi FANCC mutation patients are at significant and early risk of progression to AML, often before the presentation of aplastic anemia[98][98]. In general terms, it is thought that such a risk of early AML progression is coincident with a more severeFA phenotype[99][100][101].

Historically, the challenges of SCT in FA patients have been numerous. The issue of graft failure has a prevalence of $10 \%$, but use of fludaribine has reduced this risk to $<1 \%$. As a result, efforts at reduction of conditioning have been steady and the use of total body irradiation has been diminished down to doses of 400 to $600 \mathrm{cGy}$. In addition, the use of cyclophosphamide has also been decreased in recent years. With an allogenic-related transplant, the long-term survival is often greater than $80 \%$ [102][101].

Matched-unrelated transplants have posed a greater challenge with a greater incidence of graft-versus-host disease. Toxicity-associated graft-versus-host disease occurs with greater intensity in the FA patient, perhaps because of the greater degree of toxicity caused by 
conditioning. Such toxicity is synergistic with the increased graft-versus-host disease risk. With diminished toxicity has come greater graft-versus-host disease control and subsequent increased survival for FA patients undergoing matched-unrelated transplants[101][103].

Secondary effects of SCT have important consequences for FA patients presumably because of their underlying issues of growth delay, endocrine dysfunction, and increased risk of malignancy, all of which are associated with long-term consequences of undergoing SCT. A markedly increased risk of acquisition of SCC is seen post-transplantation beyond that observed in untransplanted FA patients; these SCC are only somewhat linked to human papillomavirus [82]. GVHD greatly increases the risk of SCC in FA patients and patients undergoing unrelated stem cell transplant.

The idea that FA cells are hypersensitive to endogenous and exogenous stimuli suggests that FA stem cells in the bone marrow are susceptible to a sort of "natural selection." This is probably why somatic reversion is observed in some FA patients. As a result, it has been postulated that gene therapy is an ideal approach to treatment of FA. Clinical trials targeting the most common complementation group, FA-A, have been instituted using a lentiviral transduction system of hematopoietic stem cells from FA patients, manipulated ex vivo. In vitro data suggest that hematopoietic stem cells can be transduced with subsequent colonyforming assays suggesting increased growth and reconstitution. Such trails have been disappointing, however, because lack of permanent transduction of progenitors has led to failure to establish long- term hematopoiesis[104][105].

Traditionally, androgens have proved to be an efficacious treatment in some bone marrow failure patients, FA patients included. Androgens can stimulate more effective hematopoiesis, resulting in an increase in peripheral blood counts. The use of androgens has been marked by their limitations in females, given the masculinizing side effects. In addition, their use has been associated with increased risk of liver adenomas[106,107].

The FA pathway is composed of at least 16 genes[108].Each of these genes, when biallelically mutated, causes FA, except for the $\mathrm{X}$ linked FANCB. The encoded proteins (Table 1) can be subdivided within the FA pathway into three groups: (1) proteins that make up the core complex; (2) the FANCD2 and FANCI proteins, which compose the ID complex; and (3) five downstream effector proteins, FANCD1/BRCA2, FANCJ/BRIP1/ BACH1, FANCN/PALB2, FANCO/SLX4, and FANCP/RAD51C. Many of the FA proteins contain no recognizable motifs, which has made discovering their contributions to the FA pathway and the main function of the FA pathway more challenging[108][109][110][111].

Teleologically, the involvement of very specific developmental abnormalities in FA patients implies that the FA proteins have the potential for other functions aside from those they perform in protecting the genome. Some have argued that the main function of the FA pathway is to regulate oxidative stress, because reactive oxygen species have been documented to be involved in bone marrow failure[112] [113],cancer[114],endocrinopathies[115],abnormalities in skin pigmentation[116],andmalformations[117].This explanation becomes even more plausible when considering the redox-related functions of some FA proteins[118][119]. Recent provocative work has supported the idea that acid aldehydes are the toxic metabolite in vivo, as mouse models knocking out enzymes that detoxify such chemicals phenocopoy FA[120].

Several lines of evidence have shown that excessive apoptosis and consequent malfunction of the hematopoietic stem cell compartment lead to progressive bone marrow failure in FA patients. The FANCC protein functions independently of the FA core complex to suppress apoptosis in hematopoietic cells in response to environmental cues, which induce expression 
or secretion of certain cytokines[121].FA patients exhibit altered expression levels of some growth factors and cytokines, including unusually high levels of intracellular tumor necrosis factor-a (TNF-a), a cytokine capable of initiating the apoptotic pathway.Neoplastic stem cell clones, however, which are resistant to these cytokines, frequently evolve in FA patients and result in leukemia. Cells from TNF-a-treated fancc-/- mice also showed increased levels of chromosomal aberrations and decreased levels of repair of DNA damage caused by reactive oxygen species, indicating that FANCC may also play a role in the cellular response to oxidative DNA damage[122,123][124].

\section{Mitochondrial Diseases}

\section{Pearson Syndrome}

Pearson syndrome is a rare sideroblastic anemia with associated exocrine pancreatic dysfunction, liver dysfunction, and renal tubule defects[125][126]. Often patients are diagnosed in the neonatal period, and Pearson syndrome has been reported as a cause of hydrops. Rarely these patients can have physical abnormalities such as retinopathy, ataxia, or muscle weakness but often present with failure to thrive or poor growth along with persistent, macrocytic anemia[127]. These cases, numbering no more than 40 reported in the literature, have been diagnosed histologically with vacuolization of bone marrow precursors[20][128]. In the 1990s, the molecular defect of Pearson syndrome was characterized, involving deletions and duplications of regions of mitochondrial DNA[129] [130]. As a result of the mitochondrial defect, the enzymes of the oxidative respiration cascade are compromised, and thus acidosis is the major component of the disease. In patients with the disease who survive the neonatal period, the anemia improves and in fact, elevations in hemoglobin have been observed. Recently, induced pluripotent stem cells have been produced that serve as a new primary cell model for Pearson's[131]. Growth factors have been used in the therapy of Pearson's but have not proved effective. Transfusions remain the mainstay of therapy, but mortality is high in early childhood from acidosis, sepsis, or liver and kidney failure. Malignancy has not been associated with this disease[132].

\section{B. Reticular dysgenesis (RD)}

This extremely rare disease almost exclusively presents in the neonatal period with leukopenia and lymphopenia and no myeloid and lymphoid precursors but usually not complete marrow aplasia[133][134][135][136]. Lymphoid tissue is generally absent. Early progenitors are probably the defective cells since two distinct lineages are affected. However, a subset of patients has anemia and thrombocytopenia. Genetic analysis has demonstrated that $\mathrm{RD}$ is of mitochondrial origin with mutations found in the adenylate kinase 2 gene[137]. The action of this gene has been postulated to be involved with the unfolded protein response, whose absence may lend to imbalance in secretory protein load. BMT has been curative in RD patients who clinically act like severe combined immune deficiency patients. Mixed results occur because of the difficulty of infant BMT, and the resulting mortality is high[138][139].

\section{Congenital Thrombocytopenias}

\section{Amegakaryocytic thrombocytopenia}

A handful of cases with isolated thrombocytopenia have been reported in patients who display none of the classic findings ofFA or thrombocytopenia/absent radii syndrome (TAR). These patients exhibit a range of developmental defects, including microcephaly, low birth weight, delay, cardiac defects, central nervous system defects, and orthopedic anomalies. The presentation of most patients includes thrombocytopenia without 
megakaryocytes on marrow examination. Progressively, an increasingly hypocellular picture emerges over time, suggesting that pancytopenia is a bigger issue than at initial presentation. A familial pattern has emerged in these patients, which fits both autosomal recessive and Xlinked inheritance. Several candidates have been identified as the causative gene, including MPL, RUNX1, ANKRD26, MYH9, and PTPN1, but the large majority of cases of mutations has been in MPL, the thrombopoietin receptor. Forty percent of patients develop pancytopenia along a variable timeline and are at risk of leukemia. Corticosteroids have been used with limited success and little BMT experience exists in this disease[20][7][140] [141].

\section{TAR syndrome}

Thrombocytopenia with absent radii (TAR) is an autosomal recessive disease with preserved thumbs. Thrombocytopenia is usually evident from birth and almost certainly by 4 months of age and is accompanied by significant hemorrhagic events. Megakaryocytes are absent, classifying it as a progenitor disease only affecting the platelet lineage. Some patients exhibit a leukemoid reaction, but this subsides in infancy. Because of the lack of malignancy, genomic instability, and no reports of FA mutations, this disease entity is likely not an overlap with FA nor a premalignant syndrome, although sporadic cases of leukemia associated with TAR exist. Platelet counts improve after infancy; thus afflicted patients do relatively well after the first year of life, requiring platelet transfusions only during infancy. Other modalities have not been shown to be effective[20][142][143].

\section{F. Congenital Dyserythropoietic Anemia (CDA)}

The CDAs are a group of isolated red cell production disorders characterized by morphological abnormalities of erythroid precursors in the bone marrow, a consequence of dyserythropoiesis and ineffective erythropoiesis[144][145]. In addition, distal limb malformations, including syndactyly, absence of phalanges and nails, an additional phalanx, and duplication or hypoplasia of the metatarsals, have been reported in several cases of CDA I[146].Other congenital abnormalities found include café au lait spots, short stature, flattened vertebral bodies, hypoplastic rib, Madelung deformity, deafness, and retinal angiod streaks[147][148].

On the basis of morphological abnormalities of the bone marrow, CDAs have been classified into three different types: type I, type II, and type III, but additional variants requiring further characterization have also been identified.Approximately 600 cases of CDA have been reported worldwide, CDA II being the most common[149].CDA II in particular has been associated with the HEMPAS phenotype (hereditary erythroidmultinuclearity with positive acidified serum). CDA I and II are inherited in an autosomal recessive pattern, and CDA III exhibits autosomal dominant inheritance and a sporadic form[144].The disease-related genes for CDA I, II, and III have been localized by linkage analysis, and the disease-causing genes have been identified for CDA I, II, and III.Additional reports suggest other distinct forms of CDA. Most of these have been tentatively assigned to four phenotype-based groups designated CDA group IV, V, VI, and VII, with varying degrees of anemia and erythroid dysplasia.They have been designated as groups rather than types as there is evidence of phenotypic and/or genetic heterogeneity within each group. In addition to these groups, each of which includes three or more families, there are cases with unique features reported in only one or two families.

Theineffective erythropoiesis of CDA leads to intermittent jaundice, splenomegaly, hepatomegaly, and iron overload,also a result of blood transfusion therapy[145][150] [151].Dyserythropoiesis results in an abnormal features of marrow erythroblasts such as 
internuclear chromatin bridges, multinuclearity, vacuolization, and duplication of the plasma membrane.

CDA I is an autosomal recessive disease marked by mutations in cdan1, whose encoded protein has no obvious function[152]. Additional variants of CDA I have demonstrated mutations in the erythroid transcription factor KLF1 in a dominant fashion[153]. CDA I is marked by spongy heterochromatin, suggesting a role for cdan1 in chromatin, and a link to the chromatin binding protein HP1 has been made[154]. CDA II is also autosomal recessive, with mutations reported in the secretory pathway gene SEC23B[155]. CDA III is an autosomal dominant disease with reported mutations in the KIF23 gene, a kinesin[156]. Given the lack of a cancer phenotype and the involvement of these gene products in chromatin and in the secretory pathway, these genes suggest a pathway for regulation of nuclear extrusion and red cell maturation and the lack of involvement in early erythropoiesis.

Treatment varies amongst groups of CDA, although generally attention to gallstones and iron overload is warranted. Splenectomy is often indicated for CDA II; less so for other groups. Interferon alpha has been shown to be efficacious, especially in CDA I[149].

\section{E. Workup of a patient with bone marrow failure}

The clinical signs of pancytopenia include infection, bruising, and pallor. A blood count,usually done by the primary care physician or emergency department, will then reveal pancytopenia. Sepsis or viral suppression can result in neutropenia and thrombocytopenia, and thus the clinical situation must be considered anytime one considers the diagnosis of hypoplastic marrow. In the absence of sepsis, a complete blood count and manual examination of the peripheral smear is mandatory. In addition, a bone marrow aspiration and biopsy are crucial to determine a primary cause. Samples should be sent for:

\section{Cytogenetics}

Culturing of mononuclear cells and examination of chromosomes for cytogenetic abnormalities is required for aplastic presentation. An abnormality indicative of malignancy, myelodysplasia, genetic syndrome (e.g., Down's), or clonal process would alter therapeutic interventions.

\section{Diepoxybutane(DEB) chromosome fragility assay}

This assay involves the incubation of a mononuclear fraction of blood cells in the presence of a bifunctional alkylating agent, that is an agent which can cause an inter or intrastrand DNA crosslink. The cells are then treated with colchicine to arrest them in mitosis and are dropped onto a slide for a karyotype-like analysis. Increased chromosome breaks in this setting are pathognomonic for Fanconi anemia. The test is very sensitive and specific. The DEB test is crucial because many FA patients bear none of the classic physical findings of FA.

\section{Flow cytometry}

Delivery of mononuclear cells into the FACs machine after fluorescent detection of surface antigens demonstrates the full panel of normal mature and precursor cells in bone marrow and peripheral blood. Detection of abnormal groups of cells reveals potential clonality or malignant process. Flow for CD55, the paroxysmal nocturnal hemoglobinuria(PNH) clone, should be performed. It is common to find a clone at low percentage but consensus is that more than approximately $15 \%$ clone would be concerning for $\mathrm{PNH}$. 


\section{Genotype analysis}

Cases in which an inherited transmission is responsible and for which a gene has been likely cloned should be analyzed for presence of mutation. For example, 16 FA genes have been cloned, and retroviral gene correction is available can establish the genetic complementation subgroup for FA as well as well as focus the search for mutations. Once the mutation is described, then effective genetic counseling may be provided for the family. CLIA-approved genetic sequencing panels now exist whereby genes in the FA, DC, DBA, and other syndromes may be interrogated for mutations, assuming some clinical suspicion.

\section{Infectious etiologies}

Titers for suspected viral causes of aplasia may be sent for IgG and IgM so the source and status of infection can be determined and followed. In some cases, PCR may be used to directly test for presence of pathogens associated with marrow aplasia. Such viruses include hepatitis, parvovirus, CMV, EBV, HHV6, and others.

\section{Telomere length analysis}

Similar to DEB testing, telomere length analysis is a functional assay to screen for dyskeratosiscongenita. The test should be done on lymphocyte subsets and not simply granulocytes or all white blood cells combined. If the results are well below the first percentile of the normal population for age then there is a high likelihood the patient has DC. Also, many patients with IBMFS have shorter telomere lengths closer to the first percentile and so it may also give some support to a clinical suspicion of an inherited process even if it is not DC.

\section{Research}

The physician should consider the collection of additional blood or marrow for research purposes per approved institutional protocol, given the rarity of marrow failure syndromes.

\section{References}

1. Narla A, Ebert BL. Ribosomopathies: human disorders of ribosome dysfunction. Blood. 2010; 115(16):3196-3205. [PubMed: 20194897]

2. Danilova N, Sakamoto KM, Lin S. Ribosomal protein S19 deficiency in zebrafish leads to developmental abnormalities and defective erythropoiesis through activation of p53 protein family. Blood. 2008; 112(13):5228-5237. [PubMed: 18515656]

3. McGowan KA, Li JZ, Park CY, et al. Ribosomal mutations cause p53-mediated dark skin and pleiotropic effects. Nature genetics. 2008; 40(8):963-970. [PubMed: 18641651]

4. Burwick N, Shimamura A, Liu JM. Non-Diamond Blackfan anemia disorders of ribosome function: Shwachman Diamond syndrome and 5q- syndrome. Seminars in hematology. 2011; 48(2):136-143. [PubMed: 21435510]

5. Diamond LK. Congenital hypoplastic anemia: Diamond-Blackfan syndrome. Historical and clinical aspects. Blood Cells. 1978; 4(1-2):209-213. [PubMed: 747770]

6. Alter BP, Nathan DG. Red cell aplasia in children. Arch Dis Child. 1979; 54(4):263-267. [PubMed: 453908]

7. Slayton WB, Schibler KR. Congenital bone marrow failure syndromes associated with protean developmental defects and leukemia. Clin Perinatol. 2000; 27(3):543-558. [PubMed: 10986628]

8. Willig TN, Gazda H, Sieff CA. Diamond-Blackfan anemia. Current opinion in hematology. 2000; 7(2):85-94. [PubMed: 10698294]

9. Willig TN, Ball SE, Tchernia G. Current concepts and issues in Diamond-Blackfan anemia. Current opinion in hematology. 1998; 5(2):109-115. [PubMed: 9570703]

10. Gray PH. Pure red-cell aplasia. Occurrence in three generations. Med J Aust. 1982; 1(12):519-521. [PubMed: 6178949] 
11. Gojic V, van't Veer-Korthof ET, Bosch LJ, et al. Congenital hypoplastic anemia: another example of autosomal dominant transmission. Am J Med Genet. 1994; 50(1):87-89. [PubMed: 8160759]

12. Viskochil DH, Carey JC, Glader BE, et al. Congenital hypoplastic (Diamond-Blackfan) anemia in seven members of one kindred. Am J Med Genet. 1990; 35(2):251-256. [PubMed: 2309764]

13. Alter BP. Thumbs and anemia. Pediatrics. 1978; 62(4):613-614. [PubMed: 714597]

14. Sieff CA, Nisbet-Brown E, Nathan DG. Congenital bone marrow failure syndromes. British journal of haematology. 2000; 111(1):30-42. [PubMed: 11091180]

15. Krijanovski OI, Sieff CA. Diamond-Blackfan anemia. Hematology/oncology clinics of North America. 1997; 11(6):1061-1077. [PubMed: 9443046]

16. Hammond D, Shore N, Movassaghi N. Production, utilization and excretion of erythropoietin. I. Chronic anemias. II. Aplastic crisis. 3. Erythropoietic effects of normal plasma. Ann N Y Acad Sci. 1968; 149(1):516-527. [PubMed: 5240745]

17. Alter BP. Fetal erythropoiesis in stress hematopoiesis. Experimental hematology. 1979; 7(Suppl 5): 200-209. [PubMed: 95616]

18. Buchanan GR, Alter BP, Holtkamp CA, et al. Platelet number and function in Diamond-Blackfan anemia. Pediatrics. 1981; 68(2):238-241. [PubMed: 7267232]

19. Giri N, Kang E, Tisdale JF, et al. Clinical and laboratory evidence for a trilineage haematopoietic defect in patients with refractory Diamond-Blackfan anaemia. British journal of haematology. 2000; 108(1):167-175. [PubMed: 10651740]

20. Alter, B.; Young, N. The Bone Marrow Failure Syndromes. In: Nathan, D.; Orkin, S., editors. Hematology of Infancy and Childhood. WB Saunders; Philadelphia: 1998. p. 237-335.

21. Sjolin S, Wranne L. Treatment of congenital hypoplastic anemia with prednisone. Scand J Haematol. 1970; 7(1):63-72. [PubMed: 5447959]

22. Vlachos A, Muir E. How I treat Diamond-Blackfan anemia. Blood. 2010; 116(19):3715-3723. [PubMed: 20651069]

23. Greinix HT, Storb R, Sanders JE, et al. Long-term survival and cure after marrow transplantation for congenital hypoplastic anaemia (Diamond-Blackfan syndrome). British journal of haematology. 1993; 84(3):515-520. [PubMed: 8217802]

24. Mugishima H, Gale RP, Rowlings PA, et al. Bone marrow transplantation for Diamond-Blackfan anemia. Bone marrow transplantation. 1995; 15(1):55-58. [PubMed: 7742755]

25. Niemeyer CM, Baumgarten E, Holldack J, et al. Treatment trial with recombinant human erythropoietin in children with congenital hypoplastic anemia. Contrib Nephrol. 1991; 88:276280. [PubMed: 2040190]

26. Gillio AP, Faulkner LB, Alter BP, et al. Treatment of Diamond-Blackfan anemia with recombinant human interleukin-3. Blood. 1993; 82(3):744-751. [PubMed: 8338944]

27. Dunbar CE, Smith DA, Kimball J, et al. Treatment of Diamond-Blackfan anaemia with haematopoietic growth factors, granulocyte-macrophage colony stimulating factor and interleukin 3: sustained remissions following IL-3. British journal of haematology. 1991; 79(2):316-321. [PubMed: 1958491]

28. Janov AJ, Leong T, Nathan DG, et al. Diamond-Blackfan anemia. Natural history and sequelae of treatment. Medicine (Baltimore). 1996; 75(2):77-78. [PubMed: 8606629]

29. Basso G, Cocito MG, Rebuffi L, et al. Congenital hypoplastic anaemia developed in acute megakarioblastic leukaemia. A case report. Helv Paediatr Acta. 1981; 36(3):267-270. [PubMed: 7196899]

30. Krishnan EU, Wegner K, Garg SK. Congenital hypoplastic anemia terminating in acute promyelocytic leukemia. Pediatrics. 1978; 61(6):898-901. [PubMed: 276838]

31. D'Oelsnitz M, Vincent L, De Swarte M, et al. [Proceedings: Acute lymphoblastic leukemia following treatment of Blackfan-Diamond's disease]. Arch Fr Pediatr. 1975; 32(6):582. [PubMed: 810109]

32. van Dijken PJ, Verwijs W. Diamond-Blackfan anemia and malignancy. A case report and a review of the literature. Cancer. 1995; 76(3):517-520. [PubMed: 8625135]

33. Seip M. Malignant tumors in two patients with Diamond-Blackfan anemia treated with corticosteroids and androgens. Pediatr Hematol Oncol. 1994; 11(4):423-426. [PubMed: 7947015] 
34. Aquino VM, Buchanan GR. Osteogenic sarcoma in a child with transfusion-dependent DiamondBlackfan anemia. Journal of pediatric hematology/oncology. 1996; 18(2):230-232. [PubMed: 8846147]

35. Willig TN, Draptchinskaia N, Dianzani I, et al. Mutations in ribosomal protein S19 gene and diamond blackfan anemia: wide variations in phenotypic expression. Blood. 1999; 94(12):4294 4306. [PubMed: 10590074]

36. Draptchinskaia N, Gustavsson P, Andersson B, et al. The gene encoding ribosomal protein S19 is mutated in Diamond-Blackfan anaemia. Nature genetics. 1999; 21(2):169-175. [PubMed: 9988267]

37. Landowski, M.; O'Donohue, MF.; Buros, C., et al. Human genetics. 2013. Novel deletion of RPL15 identified by array-comparative genomic hybridization in Diamond-Blackfan anemia.

38. Sankaran VG, Ghazvinian R, Do R, et al. Exome sequencing identifies GATA1 mutations resulting in Diamond-Blackfan anemia. The Journal of clinical investigation. 2012; 122(7):2439-2443. [PubMed: 22706301]

39. Nathan DG, Clarke BJ, Hillman DG, et al. Erythroid precursors in congenital hypoplastic (Diamond-Blackfan) anemia. The Journal of clinical investigation. 1978; 61(2):489-498. [PubMed: 621285]

40. Freedman MH, Amato D, Saunders EF. Erythroid colony growth in congenital hypoplastic anemia. The Journal of clinical investigation. 1976; 57(3):673-677. [PubMed: 1249203]

41. Lipton JM, Kudisch M, Gross R, et al. Defective erythroid progenitor differentiation system in congenital hypoplastic (Diamond-Blackfan) anemia. Blood. 1986; 67(4):962-968. [PubMed: 3955239]

42. McGuckin CP, Ball SE, Gordon-Smith EC. Diamond-Blackfan anaemia: three patterns of in vitro response to haemopoietic growth factors. British journal of haematology. 1995; 89(3):457-464. [PubMed: 7537525]

43. Perdahl EB, Naprstek BL, Wallace WC, et al. Erythroid failure in Diamond-Blackfan anemia is characterized by apoptosis. Blood. 1994; 83(3):645-650. [PubMed: 8298126]

44. Ershler WB, Ross J, Finlay JL, et al. Bone-marrow microenvironment defect in congenital hypoplastic anemia. N Engl J Med. 1980; 302(24):1321-1327. [PubMed: 7374678]

45. Cui, D.; Li, L.; Lou, H., et al. Oncogene. 2013. The ribosomal protein S26 regulates p53 activity in response to DNA damage.

46. Ellis SR. DBA, del(5q): a reciprocal relationship. Blood. 2011; 118(8):2032-2033. [PubMed: 21868584]

47. Payne EM, Virgilio M, Narla A, et al. L-Leucine improves the anemia and developmental defects associated with Diamond-Blackfan anemia and del(5q) MDS by activating the mTOR pathway. Blood. 2012; 120(11):2214-2224. [PubMed: 22734070]

48. Drachtman RA, Alter BP. Dyskeratosis congenita. Dermatol Clin. 1995; 13(1):33-39. [PubMed: 7712648]

49. Dokal I. Dyskeratosis congenita in all its forms. British journal of haematology. 2000; 110(4):768779. [PubMed: 11054058]

50. Anil S, Beena VT, Raji MA, et al. Oral squamous cell carcinoma in a case of dyskeratosis congenita. Ann Dent. 1994; 53(1):15-18. [PubMed: 8060104]

51. Dokal I. Dyskeratosis congenita. Hematology / the Education Program of the American Society of Hematology American Society of Hematology. 2011; 2011:480-486.

52. Mason PJ, Bessler M. The genetics of dyskeratosis congenita. Cancer genetics. 2011; 204(12):635645. [PubMed: 22285015]

53. Ballew BJ, Savage SA. Updates on the biology and management of dyskeratosis congenita and related telomere biology disorders. Expert review of hematology. 2013; 6(3):327-337. [PubMed: 23782086]

54. Liu JM, Ellis SR. Ribosomes and marrow failure: coincidental association or molecular paradigm? Blood. 2006; 107(12):4583-4588. [PubMed: 16507776]

55. Rackley S, Pao M, Seratti GF, et al. Neuropsychiatric conditions among patients with dyskeratosis congenita: a link with telomere biology? Psychosomatics. 2012; 53(3):230-235. [PubMed: 22458992] 
56. Pritchard SL, Junker AK. Positive response to granulocyte-colony-stimulating factor in dyskeratosis congenita before matched unrelated bone marrow transplantation. Am J Pediatr Hematol Oncol. 1994; 16(2):186-187. [PubMed: 7513138]

57. Oehler L, Reiter E, Friedl J, et al. Effective stimulation of neutropoiesis with rh G-CSF in dyskeratosis congenita: a case report. Annals of hematology. 1994; 69(6):325-327. [PubMed: 7527662]

58. Rocha V, Devergie A, Socie G, et al. Unusual complications after bone marrow transplantation for dyskeratosis congenita. British journal of haematology. 1998; 103(1):243-248. [PubMed: 9792316]

59. Knight S, Vulliamy T, Copplestone A, et al. Dyskeratosis Congenita (DC) Registry: identification of new features of DC. British journal of haematology. 1998; 103(4):990-996. [PubMed: 9886310]

60. Gadalla SM, Sales-Bonfim C, Carreras J, et al. Outcomes of Allogeneic Hematopoietic Cell Transplantation in Patients with Dyskeratosis Congenita. Biol Blood Marrow Transplant. 2013

61. Smith OP, Hann IM, Chessells JM, et al. Haematological abnormalities in Shwachman-Diamond syndrome. British journal of haematology. 1996; 94(2):279-284. [PubMed: 8759887]

62. Smith OP. Shwachman-Diamond syndrome. Seminars in hematology. 2002; 39(2):95-102. [PubMed: 11957191]

63. Boocock GR, Morrison JA, Popovic M, et al. Mutations in SBDS are associated with ShwachmanDiamond syndrome. Nature genetics. 2003; 33(1):97-101. [PubMed: 12496757]

64. Tulpule A, Kelley JM, Lensch MW, et al. Pluripotent stem cell models of shwachman-diamond syndrome reveal a common mechanism for pancreatic and hematopoietic dysfunction. Cell stem cell. 2013; 12(6):727-736. [PubMed: 23602541]

65. Burwick N, Coats SA, Nakamura T, et al. Impaired ribosomal subunit association in ShwachmanDiamond syndrome. Blood. 2012; 120(26):5143-5152. [PubMed: 23115272]

66. Barrios N, Kirkpatrick D, Regueira O, et al. Bone marrow transplant in Shwachman Diamond syndrome. British journal of haematology. 1991; 79(2):337-338. [PubMed: 1958495]

67. Adachi N, Tsuchiya H, Nunoi H, et al. rhG-CSF for Shwachman's syndrome. Lancet. 1990; 336(8723):1136. [PubMed: 1700246]

68. Dale DC, Bonilla MA, Davis MW, et al. A randomized controlled phase III trial of recombinant human granulocyte colony-stimulating factor (filgrastim) for treatment of severe chronic neutropenia. Blood. 1993; 81(10):2496-2502. [PubMed: 8490166]

69. Makitie O, Kaitila I. Cartilage-hair hypoplasia--clinical manifestations in 108 Finnish patients. Eur J Pediatr. 1993; 152(3):211-217. [PubMed: 8444246]

70. Makitie O, Sulisalo T, de la Chapelle A, et al. Cartilage-hair hypoplasia. Journal of medical genetics. 1995; 32(1):39-43. [PubMed: 7897625]

71. le Merrer M, Briard ML, Chauvet ML, et al. [Autosomal recessive metaphyseal chondrodysplasia and Hirschsprung's disease]. Ann Pediatr (Paris). 1991; 38(1):27-30. [PubMed: 2006830]

72. Ridanpaa M, van Eenennaam H, Pelin K, et al. Mutations in the RNA component of RNase MRP cause a pleiotropic human disease, cartilage-hair hypoplasia. Cell. 2001; 104(2):195-203. [PubMed: 11207361]

73. Maida Y, Yasukawa M, Furuuchi M, et al. An RNA-dependent RNA polymerase formed by TERT and the RMRP RNA. Nature. 2009; 461(7261):230-235. [PubMed: 19701182]

74. Ganapathi KA, Shimamura A. Ribosomal dysfunction and inherited marrow failure. British journal of haematology. 2008; 141(3):376-387. [PubMed: 18410571]

75. Juvonen E, Makitie O, Makipernaa A, et al. Defective in-vitro colony formation of haematopoietic progenitors in patients with cartilage-hair hypoplasia and history of anaemia. Eur J Pediatr. 1995; 154(1):30-34. [PubMed: 7895753]

76. Virolainen M, Savilahti E, Kaitila I, et al. Cellular and humoral immmunity in cartilage-hair hypoplasia. Pediatr Res. 1978; 12(10):961-966. [PubMed: 724297]

77. Makitie O, Rajantie J, Kaitila I. Anaemia and macrocytosis--unrecognized features in cartilage-hair hypoplasia. Acta Paediatr. 1992; 81(12):1026-1029. [PubMed: 1290847] 
78. Gorlin R. Cartilage-hair-hypoplasia and Hodgkin disease. Am J Med Genet. 1992; 44:539. [PubMed: 1442902]

79. Taskinen M, Jeskanen L, Karjalainen-Lindsberg ML, et al. Combating cancer predisposition in association with idiopathic immune deficiency: a recurrent nodal and cutaneous T-cell lymphoproliferative disease in a patient with cartilage-hair hypoplasia. Clinical lymphoma, myeloma \& leukemia. 2013; 13(1):73-76.

80. Alter BP. Fanconi's anemia, transplantation, and cancer. Pediatric transplantation. 2005; 9(Suppl 7):81-86. [PubMed: 16305622]

81. Lowy DR, Gillison ML. A new link between Fanconi anemia and human papillomavirusassociated malignancies. Journal of the National Cancer Institute. 2003; 95(22):1648-1650. [PubMed: 14625250]

82. Masserot C. Peffault de Latour R, Rocha V, et al. Head and neck squamous cell carcinoma in 13 patients with Fanconi anemia after hematopoietic stem cell transplantation. Cancer. 2008

83. Bagby GC, Alter BP. Fanconi anemia. Seminars in hematology. 2006; 43(3):147-156. [PubMed: 16822457]

84. D'Andrea AD, Dahl N, Guinan EC, et al. Marrow failure. Hematology / the Education Program of the American Society of Hematology American Society of Hematology. 2002:58-72.

85. Tischkowitz M, Dokal I. Fanconi anaemia and leukaemia - clinical and molecular aspects. British journal of haematology. 2004; 126(2):176-191. [PubMed: 15238138]

86 . Hirschhorn R. In vivo reversion to normal of inherited mutations in humans. Journal of medical genetics. 2003; 40(10):721-728. [PubMed: 14569115]

87. Soulier J, Leblanc T, Larghero J, et al. Detection of somatic mosaicism and classification of Fanconi anemia patients by analysis of the FA/BRCA pathway. Blood. 2005; 105(3):1329-1336. [PubMed: 15383454]

88. Velez-Ruelas MA, Martinez-Jaramillo G, Arana-Trejo RM, et al. Hematopoietic changes during progression from Fanconi anemia into acute myeloid leukemia: case report and brief review of the literature. Hematology (Amsterdam, Netherlands). 2006; 11(5):331-334.

89. Rochowski A, Olson SB, Alonzo TA, et al. Patients with Fanconi anemia and AML have different cytogenetic clones than de novo cases of AML. Pediatric blood \& cancer. 2012; 59(5):922-924. [PubMed: 22517793]

90. Mehta PA, Ileri T, Harris RE, et al. Chemotherapy for myeloid malignancy in children with Fanconi anemia. Pediatric blood \& cancer. 2007; 48(7):668-672. [PubMed: 16609946]

91. Scheckenbach K, Wagenmann M, Freund M, et al. Squamous cell carcinomas of the head and neck in Fanconi anemia: risk, prevention, therapy, and the need for guidelines. Klinische Padiatrie. 2012; 224(3):132-138. [PubMed: 22504776]

92. Somyajit K, Subramanya S, Nagaraju G. RAD51C: a novel cancer susceptibility gene is linked to Fanconi anemia and breast cancer. Carcinogenesis. 2010; 31(12):2031-2038. [PubMed: 20952512]

93. Cantor SB, Guillemette S. Hereditary breast cancer and the BRCA1-associated FANCJ/BACH1/ BRIP1. Future oncology. 2011; 7(2):253-261. [PubMed: 21345144]

94. Coulet F, Fajac A, Colas C, et al. Germline RAD51C mutations in ovarian cancer susceptibility. Clinical genetics. 2013; 83(4):332-336. [PubMed: 22725699]

95. Kobayashi, H.; Ohno, S.; Sasaki, Y., et al. Oncology reports. 2013. Hereditary breast and ovarian cancer susceptibility genes (Review).

96. Tischkowitz M, Xia B. PALB2/FANCN: recombining cancer and Fanconi anemia. Cancer research. 2010; 70(19):7353-7359. [PubMed: 20858716]

97. Do K, Chen AP. Molecular pathways: targeting PARP in cancer treatment. Clinical cancer research : an official journal of the American Association for Cancer Research. 2013; 19(5):977984. [PubMed: 23269547]

98. Meyer S, Fergusson WD, Whetton AD, et al. Amplification and translocation of 3q26 with overexpression of EVI1 in Fanconi anemia-derived childhood acute myeloid leukemia with biallelic FANCD1/BRCA2 disruption. Genes, chromosomes \& cancer. 2007; 46(4):359-372. [PubMed: 17243162] 
99. Farzin A, Davies SM, Smith FO, et al. Matched sibling donor haematopoietic stem cell transplantation in Fanconi anaemia: an update of the Cincinnati Children's experience. British journal of haematology. 2007; 136(4):633-640. [PubMed: 17367413]

100. Pasquini R, Carreras J, Pasquini MC, et al. HLA-matched sibling hematopoietic stem cell transplantation for fanconi anemia: comparison of irradiation and nonirradiation containing conditioning regimens. Biol Blood Marrow Transplant. 2008; 14(10):1141-1147. [PubMed: 18804044]

101. Gluckman E, Wagner JE. Hematopoietic stem cell transplantation in childhood inherited bone marrow failure syndrome. Bone marrow transplantation. 2008; 41(2):127-132. [PubMed: 18084332]

102. Chaudhury S, Auerbach AD, Kernan NA, et al. Fludarabine-based cytoreductive regimen and Tcell-depleted grafts from alternative donors for the treatment of high-risk patients with Fanconi anaemia. British journal of haematology. 2008; 140(6):644-655. [PubMed: 18302713]

103. Balci YI, Akdemir Y, Gumruk F, et al. CD-34 selected hematopoetic stem cell transplantation from HLA identical family members for fanconi anemia. Pediatric blood \& cancer. 2008; 50(5): 1065-1067. [PubMed: 18000858]

104. Kelly PF, Radtke S, von Kalle C, et al. Stem cell collection and gene transfer in Fanconi anemia. Mol Ther. 2007; 15(1):211-219. [PubMed: 17164793]

105. Croop JM. Gene therapy for fanconi anemia. Current hematology reports. 2003; 2(4):335-340. [PubMed: 12901331]

106. Velazquez I, Alter BP. Androgens and liver tumors: Fanconi's anemia and non-Fanconi's conditions. American journal of hematology. 2004; 77(3):257-267. [PubMed: 15495253]

107. Ozenne V, Paradis V, Vullierme MP, et al. Liver tumours in patients with Fanconi anaemia: a report of three cases. European journal of gastroenterology \& hepatology. 2008; 20(10):10361039. [PubMed: 18787475]

108. Bogliolo M, Schuster B, Stoepker C, et al. Mutations in ERCC4, encoding the DNA-repair endonuclease XPF, cause Fanconi anemia. American journal of human genetics. 2013; 92(5): 800-806. [PubMed: 23623386]

109. Kottemann MC, Smogorzewska A. Fanconi anaemia and the repair of Watson and Crick DNA crosslinks. Nature. 2013; 493(7432):356-363. [PubMed: 23325218]

110. Green AM, Kupfer GM. Fanconi anemia. Hematology/oncology clinics of North America. 2009; 23(2):193-214. [PubMed: 19327579]

111. Kee Y, D'Andrea AD. Molecular pathogenesis and clinical management of Fanconi anemia. The Journal of clinical investigation. 2012; 122(11):3799-3806. [PubMed: 23114602]

112. Gordon-Smith EC, Rutherford TR. Fanconi anaemia--constitutional, familial aplastic anaemia. Bailliere's clinical haematology. 1989; 2(1):139-152.

113. Bornman L, Baladi S, Richard MJ, et al. Differential regulation and expression of stress proteins and ferritin in human monocytes. Journal of cellular physiology. 1999; 178(1):1-8. [PubMed: 9886484]

114. Kovacic P, Jacintho JD. Mechanisms of carcinogenesis: focus on oxidative stress and electron transfer. Current medicinal chemistry. 2001; 8(7):773-796. [PubMed: 11375749]

115. Evans LM, Davies JS, Anderson RA, et al. The effect of GH replacement therapy on endothelial function and oxidative stress in adult growth hormone deficiency. European journal of endocrinology / European Federation of Endocrine Societies. 2000; 142(3):254-262. [PubMed: 10700719]

116. Memoli S, Napolitano A, d'Ischia M, et al. Diffusible melanin-related metabolites are potent inhibitors of lipid peroxidation. Biochimica et biophysica acta. 1997; 1346(1):61-68. [PubMed: 9187303]

117. Wells PG, Kim PM, Laposa RR, et al. Oxidative damage in chemical teratogenesis. Mutation research. 1997; 396(1-2):65-78. [PubMed: 9434860]

118. Cumming RC, Lightfoot J, Beard K, et al. Fanconi anemia group C protein prevents apoptosis in hematopoietic cells through redox regulation of GSTP1. Nature medicine. 2001; 7(7):814-820. 
119. Zanier R, Briot D, Dugas du Villard JA, et al. Fanconi anemia C gene product regulates expression of genes involved in differentiation and inflammation. Oncogene. 2004; 23(29):50045013. [PubMed: 15077170]

120. Langevin F, Crossan GP, Rosado IV, et al. Fancd 2 counteracts the toxic effects of naturally produced aldehydes in mice. Nature. 2011; 475(7354):53-58. [PubMed: 21734703]

121. Fagerlie SR, Koretsky T, Torok-Storb B, et al. Impaired type I IFN-induced Jak/STAT signaling in FA-C cells and abnormal CD4+ Th cell subsets in Fancc-/- mice. J Immunol. 2004; 173(6): 3863-3870. [PubMed: 15356134]

122. Ceccaldi R, Parmar K, Mouly E, et al. Bone marrow failure in Fanconi anemia is triggered by an exacerbated p53/p21 DNA damage response that impairs hematopoietic stem and progenitor cells. Cell stem cell. 2012; 11(1):36-49. [PubMed: 22683204]

123. Li J, Sejas DP, Zhang X, et al. TNF-alpha induces leukemic clonal evolution ex vivo in Fanconi anemia group C murine stem cells. The Journal of clinical investigation. 2007; 117(11):32833295. [PubMed: 17960249]

124. Pang Q, Andreassen PR. Fanconi anemia proteins and endogenous stresses. Mutation research. 2009; 668(1-2):42-53. [PubMed: 19774700]

125. Pearson HA, Lobel JS, Kocoshis SA, et al. A new syndrome of refractory sideroblastic anemia with vacuolization of marrow precursors and exocrine pancreatic dysfunction. The Journal of pediatrics. 1979; 95(6):976-984. [PubMed: 501502]

126. Fellman V, Kotarsky H. Mitochondrial hepatopathies in the newborn period. Seminars in fetal \& neonatal medicine. 2011; 16(4):222-228. [PubMed: 21680270]

127. Finsterer J. Hematological manifestations of primary mitochondrial disorders. Acta haematologica. 2007; 118(2):88-98. [PubMed: 17637511]

128. Bader-Meunier B, Rotig A, Mielot F, et al. Refractory anaemia and mitochondrial cytopathy in childhood. British journal of haematology. 1994; 87(2):381-385. [PubMed: 7947282]

129. Rotig A, Cormier V, Blanche S, et al. Pearson's marrow-pancreas syndrome. A multisystem mitochondrial disorder in infancy. The Journal of clinical investigation. 1990; 86(5):1601-1608. [PubMed: 2243133]

130. Casademont J, Barrientos A, Cardellach F, et al. Multiple deletions of mtDNA in two brothers with sideroblastic anemia and mitochondrial myopathy and in their asymptomatic mother. Hum Mol Genet. 1994; 3(11):1945-1949. [PubMed: 7874110]

131. Cherry AB, Gagne KE, McLoughlin EM, et al. Induced Pluripotent Stem Cells with a Pathological Mitochondrial DNA Deletion. Stem cells. 2013

132. Fleming W, Trounce I, et al. Cytokine treatment improves the hematologic manifestations of Pearson's syndrome. Blood. 1994; 84(supp 1):27a. [PubMed: 8018921]

133. Vaal OD, Seynhaeve V. Reticular dysgenesia. Lancet. 1959; 2:1123. [PubMed: 13840590]

134. Bujan W, Ferster A, Azzi N, et al. Use of recombinant human granulocyte colony stimulating factor in reticular dysgenesis. British journal of haematology. 1992; 81(1):128-130. [PubMed: 1381605]

135. Bujan W, Ferster A, Sariban E, et al. Effect of recombinant human granulocyte colonystimulating factor in reticular dysgenesis. Blood. 1993; 82(5):1684. [PubMed: 7689877]

136. Azcona C, Alzina V, Barona $\mathrm{P}$, et al. Use of recombinant human granulocyte-macrophage colony stimulating factor in an infant with reticular dysgenesis. Eur J Pediatr. 1994; 153(3):164-166. [PubMed: 8181497]

137. Pannicke U, Honig M, Hess I, et al. Reticular dysgenesis (aleukocytosis) is caused by mutations in the gene encoding mitochondrial adenylate kinase 2. Nature genetics. 2009; 41(1):101-105. [PubMed: 19043417]

138. Levinsky RJ, Tiedeman K. Successful bone-marrow transplantation for reticular dysgenesis. Lancet. 1983; 1(8326 Pt 1):671-672. [PubMed: 6132037]

139. Roper M, Parmley RT, Crist WM, et al. Severe congenital leukopenia (reticular dysgenesis). Immunologic and morphologic characterizations of leukocytes. Am J Dis Child. 1985; 139(8): 832-835. [PubMed: 3875278] 
140. Ballmaier M, Germeshausen M. Congenital amegakaryocytic thrombocytopenia: clinical presentation, diagnosis, and treatment. Seminars in thrombosis and hemostasis. 2011; 37(6):673681. [PubMed: 22102270]

141. Stoddart MT, Connor P, Germeshausen M, et al. Congenital Amegakaryocytic Thrombocytopenia (CAMT) Presenting as Severe Pancytopenia in the First Month of Life. Pediatric blood \& cancer. 2013

142. Fadoo Z, Naqvi SM. Acute myeloid leukemia in a patient with thrombocytopenia with absent radii syndrome. Journal of pediatric hematology/oncology. 2002; 24(2):134-135. [PubMed: 11990700]

143. Go RS, Johnston KL. Acute myelogenous leukemia in an adult with thrombocytopenia with absent radii syndrome. European journal of haematology. 2003; 70(4):246-248. [PubMed: 12656750]

144. Iolascon A, Esposito MR, Russo R. Clinical aspects and pathogenesis of congenital dyserythropoietic anemias: from morphology to molecular approach. Haematologica. 2012; 97(12):1786-1794. [PubMed: 23065504]

145. Wickramasinghe SN. Congenital dyserythropoietic anaemias: clinical features, haematological morphology and new biochemical data. Blood reviews. 1998; 12(3):178-200. [PubMed: 9745888]

146. Parez N, Dommergues M, Zupan V, et al. Severe congenital dyserythropoietic anaemia type I: prenatal management, transfusion support and alpha-interferon therapy. British journal of haematology. 2000; 110(2):420-423. [PubMed: 10971401]

147. Halpern Z, Rahmani R, Levo Y. Severe hemochromatosis: the predominant clinical manifestation of congenital dyserythropoietic anemia type 2 . Acta haematologica. 1985; 74(3):178-180. [PubMed: 3938164]

148. Sandstrom H, Wahlin A, Eriksson M, et al. Intravascular haemolysis and increased prevalence of myeloma and monoclonal gammopathy in congenital dyserythropoietic anaemia, type III. European journal of haematology. 1994; 52(1):42-46. [PubMed: 8299769]

149. Wickramasinghe SN, Wood WG. Advances in the understanding of the congenital dyserythropoietic anaemias. British journal of haematology. 2005; 131(4):431-446. [PubMed: 16281933]

150. Vainchenker W, Breton-Gorius J, Guichard J, et al. Congenital dyserythropoietic anemia type III. studies on erythroid differentiation of blood erythroid progenitor cells (BFUE) in vitro. Experimental hematology. 1980; 8(8):1057-1062. [PubMed: 7202587]

151. Vainchenker W, Guichard J, Bouguet J, et al. Congenital dyserythropoietic anaemia type I: absence of clonal expression in the nuclear abnormalities of cultured erythroblasts. British journal of haematology. 1980; 46(1):33-37. [PubMed: 7426450]

152. Dgany O, Avidan N, Delaunay J, et al. Congenital dyserythropoietic anemia type I is caused by mutations in codanin-1. American journal of human genetics. 2002; 71(6):1467-1474. [PubMed: 12434312]

153. Arnaud L, Saison C, Helias V, et al. A dominant mutation in the gene encoding the erythroid transcription factor KLF1 causes a congenital dyserythropoietic anemia. American journal of human genetics. 2010; 87(5):721-727. [PubMed: 21055716]

154. Renella R, Roberts NA, Brown JM, et al. Codanin-1 mutations in congenital dyserythropoietic anemia type 1 affect HP1 \{alpha\} localization in erythroblasts. Blood. 2011; 117(25):6928-6938. [PubMed: 21364188]

155. Schwarz K, Iolascon A, Verissimo F, et al. Mutations affecting the secretory COPII coat component SEC23B cause congenital dyserythropoietic anemia type II. Nature genetics. 2009; 41(8):936-940. [PubMed: 19561605]

156. Liljeholm M, Irvine AF, Vikberg AL, et al. Congenital dyserythropoietic anemia type III (CDA III) is caused by a mutation in kinesin family member, KIF23. Blood. 2013; 121(23):4791-4799. [PubMed: 23570799] 


\section{Key Points}

1. In spite of the rarity of inherited bone marrow failure syndromes (IBMFS), they represent diseases for which the molecular pathogenesis may be elucidated.

2. Their study and presentation of the details of their molecular biology and biochemistry is warranted not only for appropriate diagnosis and management of afflicted patients but also because they lend clues to the normal physiology of the normal hematopoiesis and, in many cases, mechanisms of carcinogenesis.

3. Several themes have emerged within each subsection of IBMFS, including the ribosomopathies that entail both ribosome assembly as well as ribosomal RNA processing.

4. The Fanconi anemia (FA) pathway itself has become interdigitated with the familial breast cancer syndromes. 
Table 1

\begin{tabular}{|l|l|l|l|l|}
\hline Syndrome & Inheritance pattern & Genes & Physical findings & Laboratory testing \\
\hline Fanconi Anemia & AR, XLR & $\begin{array}{l}\text { FA-A---FA-P } \\
\text { Breast cancer genes }\end{array}$ & $\begin{array}{l}\text { Short stature, radial } \\
\text { limb, thumb, }\end{array}$ & $\begin{array}{l}\text { Diepoxybutane } \\
\text { (DEB) } \\
\text { chromosome } \\
\text { breakage MMC } \\
\text { breakage assay } \\
\text { Gene testing }\end{array}$ \\
\hline DyskeratosisCongenita & AR, AD, XLR & $\begin{array}{l}\text { TERT TERC,DKC, } \\
\text { TINF2, } \\
\text { NOP10,TCAB1,NHP2 }\end{array}$ & Nails, skin, leukoplakia & $\begin{array}{l}\text { Telomere lengths } \\
\text { lymph subsets } \\
\text { Gene testing }\end{array}$ \\
\hline Shwachmann Diamond & AR & SBDS & $\begin{array}{l}\text { Pancreatic } \\
\text { insufficiency, skeletal } \\
\text { abnornalities }\end{array}$ & $\begin{array}{l}\text { Serum trypsinogen, } \\
\text { Isoamylase, fecal } \\
\text { elastase, pancreatic } \\
\text { imaging } \\
\text { Genet testing }\end{array}$ \\
\hline Diamond Blackfan anemia & & $\begin{array}{l}\text { RPS7 RPL5 } \\
\text { RPS17 RPL11 } \\
\text { RPS24 RPL15 } \\
\text { RPS26 }\end{array}$ & $\begin{array}{l}\text { Short stature, head, } \\
\text { upper limbs, urogenital }\end{array}$ & $\begin{array}{l}\text { Erythrocyte } \\
\text { adenosine } \\
\text { deaminase (ADA) } \\
\text { Gene testing }\end{array}$ \\
\hline Congenital Amegakaryocytic thrombocytopenia & AR & AD & C-MPL & \\
\hline
\end{tabular}

